Research Division

Federal Reserve Bank of St. Louis

Working Paper Series

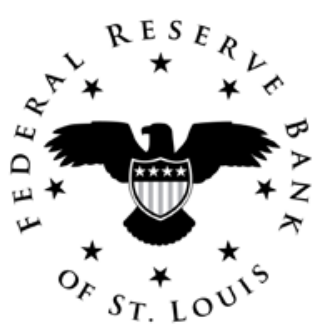

Conflict, Evolution, Hegemony, and the Power of the State

\author{
David K. Levine \\ and \\ Salvatore Modica
}

Working Paper 2013-023A

http://research.stlouisfed.org/wp/2013/2013-023.pdf

July 2013

FEDERAL RESERVE BANK OF ST. LOUIS
Research Division
P.O. Box 442
St. Louis, MO 63166

The views expressed are those of the individual authors and do not necessarily reflect official positions of the Federal Reserve Bank of St. Louis, the Federal Reserve System, or the Board of Governors.

Federal Reserve Bank of St. Louis Working Papers are preliminary materials circulated to stimulate discussion and critical comment. References in publications to Federal Reserve Bank of St. Louis Working Papers (other than an acknowledgment that the writer has had access to unpublished material) should be cleared with the author or authors. 


\title{
Conflict, Evolution, Hegemony, and the Power of the State
}

\author{
David K. Levine ${ }^{1}$, Salvatore Modica ${ }^{2}$
}

\begin{abstract}
In a model of evolution driven by conflict between societies more powerful states have an advantage. When the influence of outsiders is small we show that this results in a tendency to hegemony. In a simple example in which institutions differ in their "exclusiveness" we find that these hegemonies will be inefficiently "extractive" in the sense of having inefficiently high taxes, high compensation for state officials, and low welfare.

JEL Classification Numbers: D74 (Conflict Resolution), C73 (Evolutionary Games), D02 (Institutions)
\end{abstract}

Keywords: Evolution, Conflict, Hegemony, State Power

\footnotetext{
${ }^{4}$ First Version: April 23, 2011. We are especially grateful to Sam Bowles for his very detailed comments. We are also grateful to Daron Acemoglu, Costas Azariadis, Michele Boldrin, Drew Fudenberg, Xavier Gabaix, Philip Hoffman, Jean-Laurent Rosenthal, Debraj Ray, the members of the graduate reading group at Washington University in St. Louis and a number of anonymous referees. Seminar participants at the Bristol, the ISNIE Meetings, University of Naples, Caltech, the University of Iowa, the St. Louis Federal Reserve Bank, NYU, Bocconi and Warwick all made valuable suggestions. Part of this research was conducted while Levine was a Braudel Fellow at the European University Institute. We are grateful to Rongsheng Tang for proof-reading and to the EIEF, to NSF Grant SES-08-51315 and to the MIUR for financial support.

${ }^{*}$ Corresponding author David K. Levine, 1 Brooking Dr., St. Louis, MO, USA 63130

Email addresses: david@dklevine.com (David K. Levine), salvatore.modica@unipa.it (Salvatore Modica)

${ }^{1}$ Department of Economics, WUSTL

${ }^{2}$ Università di Palermo
} 


\section{Introduction}

A robust finding of the game theory literature is that with the possibility of future punishment and rewards there are many possible equilibria. One interpretation is that these represent alternative social norms or institutions. Indeed, we do observe a wide array of different institutions both across space and time: political systems in particular range from relatively autocratic ("exclusive" in our terminology) to quite democratic ("inclusive" in the terminology of Acemoglu and Robinson [3]). A natural question is the positive one: among these different institutions are we more likely to observe some than others? Are efficient institutions likely to be more successful than inefficient ones? A natural setting for this question is an evolutionary one and one possible answer is that of Ely $[25]^{3}$ who shows how voluntary migration leads to efficiency. But we do not believe that historically people have moved from one location to another through a kind of voluntary immigration into the arms of welcoming neighbors. Rather people and institutions have more often spread through invasion and conflict. Moreover, institutional change has generally arisen in the aftermath of the disruption caused by warfare and other conflict between societies. This leads us to address the question of which institutions are likely to be long-lived in the context of evolution driven by conflict between societies.

When evolution is driven by conflict we find that the long-run favors not institutions that maximize welfare or per capita output, but rather institutions that maximize state power. These institutions have inefficiently high taxes and state power and are not terribly inclusive. While these state power maximizing institutions are hegemonic (within their geographical area of influence) for long periods of time, these hegemonies are periodically broken with shorter periods of conflict between competing - and possibly more efficient - states.

The idea of history being dominated by hegemonic states may seem a strange one, but with some important exceptions it is borne out by historical facts. ${ }^{4}$ Take, for example, the largely geographically isolated region of China: bounded by jungles

\footnotetext{
${ }^{3}$ Ely uses a model similar to the one used here, but similar results using more biologically oriented models have been around for some time. For example Aoki [1] uses a migration model to study efficiency, while more recently Rogers, Deshpande and Feldman [45] use a migration model to show how unequal resources can lead to long-run inequality.

${ }^{4}$ Sources and calculations of historical data on hegemonies and population is in Appendix 1.
} 
in the South, deserts on the West, cold arid wasteland in the North and the Pacific Ocean in the East. We find that during the 2,234 years beginning from when we have decent historical records in $221 \mathrm{BCE}$ the area was ruled by a hegemonic state roughly $72 \%$ of the time, with five interregna. Less reliable records exist for the area of Egypt, but in the 1,617 years from 2686 BCE to the end of the new Kingdom in $1069 \mathrm{BCE}$ we see hegemonic rule $87 \%$ of the time with two interregna. In Persia during the 1,201 years from $550 \mathrm{BCE}$ to $651 \mathrm{CE}$ we see hegemony $84 \%$ of the time with two interregna. England has been largely hegemonic within the geographically confined area of the island of Britain for 947 years from $1066 \mathrm{CE}$ to the present. The Roman Empire ruled the Mediterranean area as a hegemony for 422 years from the advent of Augustus in $27 \mathrm{BCE}$ to the permanent division into Eastern and Western Empires in $395 \mathrm{CE}$ and the Eastern Roman Empire lasted an additional 429 years until the advent of the Caliphate in $814 \mathrm{CE}$. The Ottoman Empire lasted 304 years from the conquest of Egypt in $1517 \mathrm{CE}$ to the Greek revolution in $1821 \mathrm{CE}$.

There are also, however, two glaring exceptions: except for brief periods neither the subcontinent of India nor, following the fall of the Western Roman Empire, the area of continental Europe were subject to a hegemonic state.

Our theory predicts hegemony only under conditions where geography does not matter, and we would argue that in the cases of both continental Europe and India the influence of outsiders protected by strong geographical barriers was important. In the case of Europe following the fall of Rome and up to around 1066 we have the continued interference of northerners - the Vikings especially were well protected by their own geography. Following 1066 we have the constant interference of England - also safe behind a water barrier: during this period we observe that England constantly intervened in continental conflicts but always to support the weaker side, and eventually this policy of balance of power became explicit. ${ }^{5}$ India also was subject to repeated invasion from central Asia - protected not by water but by difficult desert and mountain terrain. ${ }^{6}$ Of course China too was subject to outside influence

\footnotetext{
${ }^{5}$ It is not completely correct to view England and Scandinavia as "outsiders" as at various time they had continental interests and conversely, but the key point is that they had a core area relatively safe from invasion. In a different direction Hoffman [32] argues a role also for the Western Catholic church which in Europe, and only there, has acted as a balancing force much akin to to the outsiders of our model.

${ }^{6}$ The exact nature of the asymmetry in the physical geographical barrier is uncertain, but it is a fact that India has been invaded numerous times successfully from Central Asia, but there have been no successful conquests of Central Asia from India. Phil Hoffman in a private communication
} 
- particularly that of the Mongols. However, the relative size of the Mongolia is quite small relative to China - less than half a percent of the population - while the population of Scandinavia was about $5 \%$ that of continental Europe, that in central Asia about $5 \%$ that of India, while England was about $8 \%$ of continental Europe. These exceptions are in fact exactly what is predicted by our evolutionary theory: we show that as outside influence grows the fraction of time hegemony will reign decreases. ${ }^{7}$

With respect to institutions, as we indicated, states with greater power will have an advantage over less powerful states. To focus thinking we examine a simple model in which institutions and incentives determine state power. A key question is why individuals in a society will contribute to state power? First, there is a significant public goods problem. Worse, given that outside conquest and disruption is relatively rare, it is hard to believe that military spending levels would stand much of a cost-benefit analysis, so that the "good" of state power is perhaps not very good at all. Hence while the public goods problem may be solved by a state run by officials who collect taxes, the question remains why these officials do not collude to consume tax revenue rather than use it to augment the power of the state. The answer we propose to this question is that the incentive of state officials to acquire state power is not so much in defense of the state from intruders but rather to collect taxes from which they can consume and to maintain themselves in office. Roughly speaking we view state officials as preferring to consume "jewelry" rather than "swords," but they need the swords to collect the tax revenue to pay for the jewelry. We model this in a simple way by assuming that greater state power increases the ability of the state to collect taxes. Of course a more powerful state enables the collection of greater revenues for officials only if the army and other forces of state power respond to the wishes of those officials. Whether this is true depends on inclusivity of institutions.

suggests that part of the answer may lie in the fact that the area of Central Asia is well suited for raising horses and India is not, and that horses play a central military role in conflict between Central Asia and India.

${ }^{7}$ Note that geographical factors matter in our argument only in so far as they give rise to outsiders who influence the evolution of the relationships between the other groups. An existing literature, including Diamond [20], gives physical geography a direct role, arguing for example that the terrain of Western Europe is more defensible than that of China, hence less susceptible to hegemony. Besides this particular claim being challenged on physical grounds (Hoffman [32]), such considerations have no bite in the Indian case. Incidentally: while this discussion includes only the area of Europe, Asia and North Africa, it should be borne in mind that until modern times $90 \%$ of the world population lived in this area. 
In an inclusive democracy, for instance, this is not so much the case - officials may try to send the army into the streets to collect revenues for their own benefit, but in a meaningful democracy the army will be loyal to institutions not persons and will not follow such orders.

Putting the paper in context, the idea that evolution can lead to both cooperation and inefficiency is scarcely new, nor is the idea that evolutionary pressure may be driven by conflict. There is a long literature on group selection in evolution: there may be positive assortative matching as discussed by Bergstrom [6]. Or there can be noise that leads to a trade-off between incentive constraints and group welfare as in the work of Price [42, 43]. Yet another approach is through differential extinction as in Boorman and Levitt [10]. Conflict, as opposed to migration, as a source of evolutionary pressure is examined in Bowles [12], who shows how intergroup competition can lead to the evolution of altruism. Bowles, Choi and Hopfensitz [14] and Choi and Bowles [16] study in group altruism versus out group hostility in a model driven by conflict. Rowthorn and Seabright [46] explain a drop in welfare during the neolithic transition as arising from the greater difficulty of defending agricultural resources. More broadly, there is a great deal of work on the evolution of preferences as well as of institutions: for example Blume and Easley [9], Dekel, Ely and Yilankaya [19], Alger and Weibull [5], Levine et al [36] or Bottazzi and Dindo [11]. Some of this work is focused more on biological evolution than social evolution. As Bisin [7] and Bisin and Topa [8] point out the two are not the same.

This paper is driven by somewhat different goals than earlier work. We are interested in an environment where individual incentives matter; and in an environment where the selection between the resulting equilibria are driven by conflict over resources ("land"). By combining the idea of the conflict resolution function introduced by Hirshleifer [31] and subsequently studied in the economic literature on conflict ${ }^{8}$ with the stochastic tools of Kandori, Mailath and Rob [35], Young [49] and Ellison [24] we are able with relatively weak assumptions to show when state power maximizing hegemonies do and do not arise.

\footnotetext{
${ }^{8}$ See, for example, Garfinkel and Skaperdas [29] or Hausken [30]. An important focus of this literature has been in figuring out how shares of resources are determined by the conflict resolution function.
} 


\section{A Static Example}

We start with a simple static model of how state power is determined by institutions and incentives within a society. The "size" of a society, in terms of land resources controlled, will play a crucial role in in the evolutionary dynamics, but as we assume constant returns to scale in land, land plays no role in the statics, so here we conduct the analysis per unit of land. As summarized in the introduction, the idea for this model is that state power determines strength in conflict, but officials determine state power to collect taxes in their own interest. The results of the section relate state power and welfare to the exclusivity of institutions and their extractiveness.

There are two types of players: producers $i=P$ and state officials $i=O$. The choice variable for producers is the effort level $a^{P} \in[0,1]$ and for officials the level of state power $a^{O} \in[0,1]$. State officials move first and choose the level of state power; producers move second and choose the effort level.

Internally state power serves the purpose of collecting taxes. Specifically the tax rate is determined by the level of state power $a^{O}$ together with a parameter $\chi \in[0,1]$ describing social institutions. The institutions that give rise to $\chi$ we view as fixed in the short-run described here although in the dynamic model they will change over time in response to evolutionary pressures. ${ }^{9}$ The relevant aspect of institutions summarized by the parameter $\chi$ describes the extend to which institutions enable the use of state power to collect taxes. ${ }^{10}$ It represents the "exclusivity" of those institutions: relatively inclusive institutions, such as democratic one, use a variety of checks and balances to limit the application of state power - courts, appeals processes and so forth. In the extreme when $\chi=0$ we imagine that it is essentially impossible to collect taxes because individuals who fail to pay taxes may engage in endless appeal to the courts. At the opposite extreme when $\chi=1$ tax collectors can simply seize resources from producers at gunpoint without any institutional constraint. Hence we define tax power $b=\chi a^{O}$ as the product of the exclusivity parameter $\chi$

\footnotetext{
${ }^{9}$ We do not explicitly model the decisions to adhere to social norms that underly institutions: we refer the reader to the literature on repeated games such as Fudenberg and Maskin [28] or Fudenberg Levine and Maskin [27] and especially Kandori [34]'s work on social norms. In an earlier version of this paper Levine and Modica [37] these decisions were explicitly analyzed without however leading to different conclusions.

${ }^{10}$ For computational simplicity in analyzing statics $\chi$ and $a^{i}$ will be treated as continuous, but in the analysis of evolutionary dynamics they will be treated as discrete.
} 
and target state power. When $\chi=0$ there is no tax power; when $\chi=1$ tax power is the same as state power. The actual tax rate is given by $\bar{\tau} \equiv \min \{1, \tau b\}$ where $\tau$ is a technological parameter specifying how effective tax power is in collecting taxes. We assume $\tau>1$; otherwise as we show in the appendix optimal state power is zero for all $\chi$.

Producers are represented by a single representative player. Effort translates into output one for one. Producer's utility is output net of taxes and the quadratic cost of providing effort, plus a benefit from public goods provided through state power:

$$
u^{P}=(1-\bar{\tau}) a^{P}-\left[c a^{P}+(1 / 2)(1-c)\left(a^{P}\right)^{2}\right]+\gamma a^{O} \quad 0<c<1
$$

Note that the cost function has been normalized so that the marginal cost of a unit of effort is 1 and that $\gamma$ measures the extent to which state power is useful in providing public goods.

State officials act collusively as the residual claimants of tax revenue net of the resources devoted to building state power: their utility is

$$
u^{O}=\bar{\tau} a^{P}-a^{O} .
$$

Notice that we allow negative utility for state officials - implicitly they have resources so that the state can operate with a deficit. Our results are not sensitive to this modeling simplification as in equilibrium officials never choose to do this.

An action profile $\left(a^{P}, a^{O}\right)$ for a society is an equilibrium if it is subgame perfect when the officials move first, or equivalently, a Stackelberg equilibrium. Results for the quadratic case are worked out in Appendix 2 with a complete analysis in Web Appendix 2. The economy can be summarized by means of the tax-revenue function

$$
G(b)=\tau b\left[1-\frac{\bar{\tau}}{1-c}\right]
$$

(where the term in square brackets is the producer's optimal action) and the profit function

$$
\Pi(b)=G(b)+u^{P}-\gamma a^{O}=G(b)+\frac{1-c}{2}\left[1-\frac{\bar{\tau}}{1-c}\right]^{2}
$$

Note that the utility of the representative producer and state officials are measured in compatible units in the sense that a unit of utility lost by the producer in taxes is a unit of utility gained by the state officials so that welfare $W(b)=u^{P}+u^{O}$ is 
given by $\Pi(b)-(1-\gamma) a^{O}$. The utility of state officials is $G(b)-a^{O}$.

In Web Appendix 2 we find that the salient facts about these functions are the following: $G(b)=0$ at $b=0$ and for $b \geq \bar{b} \equiv(1-c) / \tau$ while for $0 \leq b \leq \bar{b} G(b)$ is twice continuously differentiable with $G^{\prime \prime}(b)<0$; since $\tau>1$ we have $G^{\prime}(0)>1$; and $G^{\prime}(b)+b G^{\prime \prime}(b)$ is decreasing. For $0 \leq b \leq \bar{b}$ we have profits $\Pi(b)$ twice continuously differentiable, decreasing and $\Pi^{\prime \prime}(b)<0$ with $\Pi(b)=0$ for $b \geq \bar{b}$. Finally, $\Pi(b)-G(b)$ is decreasing. Stepping beyond the linear/quadratic case, when these properties are satisfied we will refer to the economy as proper.

We are interested in which institutions achieve specific benchmarks. Specifically in proper economies, we can describe institutions $\chi$ for which the equilibrium maximizes state power and for which it maximizes welfare. In Appendix 2 we show that:

Theorem 1. In a proper economy there is a unique equilibrium level of state power $a^{O}(\chi)$, and it is single peaked in $\chi$; so there is a unique argmax $\chi^{*}>0$. There is a unique welfare maximizing level of exclusivity $\hat{\chi}$, and $\hat{\chi} \leq \chi^{*}$. There is a $\bar{\gamma} \geq 1$ such that if $\gamma \leq \bar{\gamma}$ then $\hat{\chi}<\chi^{*}$.

This says that state power maximization leads to greater exclusiveness than welfare maximization.

We also have a relationship between exclusivity and what Acemoglu and Robinson [2] call extractiveness. In Appendix 2 we show that:

Theorem 2. In a proper economy profits $\Pi\left(\chi a^{O}(\chi)\right)$ are decreasing in $\chi$, while tax revenues $G\left(\chi a^{O}(\chi)\right)$, tax power $\chi a^{O}(\chi)$, and the utility of state officials $u^{O}\left(\chi, a^{O}(\chi)\right)$ are all increasing in $\chi .{ }^{11}$ For $\chi \geq \hat{\chi}$ producer utility is decreasing in $\chi$ and if $\gamma<1$ so is welfare. If $\gamma \geq 1$ the welfare is decreasing for $\hat{\chi} \leq \chi \leq \chi^{*}$.

In particular Theorem's 1 and 2 imply that institutions that maximize state power have greater extractiveness than those that maximize welfare.

\section{Dynamics with Two Societies}

We now wish to consider how institutions $\chi$ are determined by evolutionary pressure. To begin, we analyze a greatly simplified evolutionary dynamic. Subsequently we show that the qualitative properties of this example hold under much broader conditions.

\footnotetext{
${ }^{11}$ We have not specified a relationship between tax power and the tax rate, but expect that as in the linear quadratic case the tax rate is increasing in tax power.
} 
In our preliminary analysis we assume that there are two societies, that both are proper economies, and that equilibrium action profiles are always chosen. These societies share the same technology and differ only in inclusiveness $\chi$. To focus thoughts, it is useful to think of one value of $\chi$ maximizing welfare, the other maximizing state power. These two societies will compete over land, with their chances of winning or losing land governed by a conflict resolution function that depends upon relative state power. It is no surprise then that evolutionary forces will favor the society with greater state power. Our main questions concerns not "does more state power do better?" but rather, "how much better does greater state power enable a society to do?" and "how often we are likely to see a hegemony?"

Assume then that two societies $j=1,2$ compete over an integral number $L$ units of land. Both societies are assumed to implement their unique equilibrium profile, and consequently generate $a_{j}^{O}>0$ units of state power per unit of land, $j=1,2$. Without loss of generality we assume $a_{1}^{O} \leq a_{2}^{O}$, that is, society 1 is the weaker society. At time $t$ society $j$ controls an integral number $L_{j t} \geq 0$ units of land where $L_{1 t}+L_{2 t}=L$. Recall that we assume constant returns to scale in land.

Control over land follows a Markov process with state variable $L_{1 t}$, the amount of land belonging to the weaker society. The transition probabilities are determined by a conflict resolution function, in which each period there may be conflict resulting in one of the two societies losing a unit of land to the other: that is $\left|L_{j, t+1}-L_{j t}\right| \leq 1$. The conflict resolution probabilities will depend on the power of the two societies.

As there are constant returns to scale in land, we define aggregate state power as $L_{j t} a_{j}^{O}$. We refer to the loss of a unit of land as a disruption and assume that the probability of disruption depends on the force ratio:

$$
\phi_{j t}=\frac{A_{0}+L_{j t} a_{j}^{O}}{A_{0}+L_{-j, t} a_{-j}^{O}},
$$

where the constant $A_{0}>0$ represents the strength of outside forces who are safe behind geographical barriers, but who are equally disruptive towards both societies. Letting $0<p<1 / 2$ be a fixed number, we assume a kind of threshold effect: once $\phi_{j t}$ falls below a threshold $\underline{\phi}>1$ the probability of disruption becomes equal to $p$ (which is interpreted as relatively high). Above the threshold, we assume that the probability of disruption is much smaller; specifically, fix a number $\epsilon>0$ measuring 
"how small is small," then the probability of disruption is given by

$$
\pi_{j t}=p \epsilon^{\phi_{j t}-\underline{\phi}} .
$$

If we define the resistance $r_{j t}=\max \left\{0, \phi_{j t}-\underline{\phi}\right\}$ we may write $\pi_{j t}=p \epsilon^{r_{j t}}$. This may be interpreted as resistance to disruption as the probability $\pi_{j t}$ is decreasing in $r_{j t}$.

The conflict resolution function is governed by four parameters: $p, A_{0}, \epsilon, \underline{\phi}$. The first parameter $p$ determines how often land is won or lost - we may think of this as a measure of the period length - if the period is very short, then there is little chance a unit of land is lost in a single period. For a fixed period length $p$ controls how quickly change takes place - a higher value of $p$ effectively speeds up the time scale. This can be significant for applications, as $p$ can be determined by technology and geography that will generally differ across time and space. For example, it may be that a lower value of $p$ in Western Europe led to an "interregnum" that was long in absolute terms relative to China. ${ }^{12}$

Turning to the other parameters, below the threshold $\underline{\phi}$ a society is not "safe" in the sense that it has an appreciable chance of losing land. Above the threshold, it is "safe" in the sense that it has little chance of losing land. The outside forces $A_{0}$ determine how easy it is to get past the threshold - with strong outsiders it is hard to be "safe" because of the threat of the outsiders. The parameter $\epsilon$ by contrast measures how safe is "safe:" when $\epsilon=0$, for example, safe means safe forever.

Finally, to simplify the computations, we want to assume that the threshold is such that a society with even $L-1$ units of land is below the threshold. In other words, once the enemy gets a foothold, they have an appreciable chance of causing further disruption. We make this assumption only for the purposes of this example. Specifically, we assume that the force ratio with $L-1$ units of land for the stronger society $\left(A_{0}+(L-1) a_{2}^{O}\right) /\left(A_{0}+a_{1}^{O}\right) \leq \underline{\phi}$. Define

$$
\rho_{j}=\max \left\{0, \frac{A_{0}+L a_{-j}^{O}}{A_{0}}-\underline{\phi}\right\}
$$

to be the resistance to society $j$ gaining a unit of land when landless (increasing in the defender power $A_{0}+L a_{-j}^{O}$ ).

We can summarize then the Markov process: when society $j$ has no land it has

\footnotetext{
${ }^{12}$ Noting that Western Europe is de facto a hegemony now so that the "interregnum" has ended.
} 
a probability of $p \epsilon^{\rho_{j}}$ chance of getting one. When a society has at least one unit of land, but is not yet a hegemony, it has a chance $p$ of getting another unit and a chance $p$ of losing one, while if it is a hegemony, it has only a $p \epsilon^{\rho_{-j}}$ of losing a unit of land.

To understand the dynamics, observe first that when $\epsilon=0$ the hegemonic states $\left(L_{1}=L\right.$ or $\left.L_{1}=0\right)$ are absorbing and the non-hegemonic states $\left(0<L_{1}<L\right)$ are transient, so in the long-run there is a hegemony, and if the initial condition is uniform over $L_{1}$, each society has an equal chance of having the long-run hegemony since the Markov process is symmetric in this case.

When $\epsilon>0$ the situation is quite different: all states are positively recurrent and there is a unique stationary probability distribution representing the frequency with which each state occurs. Since this is a simple birth-death chain, the stationary probabilities can be explicitly computed. In particular the stationary probability of society $j$ having a hegemony is

$$
\sigma_{j}=\frac{1}{1+(L-2) \epsilon^{\rho_{-j}}+\epsilon^{\rho_{-j}-\rho_{j}}} .
$$

We can manipulate this expression to characterize the average frequency of time the system spends in hegemony:

Theorem 3. If $A_{0} \geq L a_{2}^{O} /(\phi-1)$ the stationary distribution over states is uniform regardless of $\epsilon$. If $A_{0}<L a_{2}^{O} \overline{/}(\phi-1)$ then as $\epsilon \rightarrow 0$ we have $\sigma_{1}+\sigma_{2} \rightarrow 1$. If $a_{2}^{O}>a_{1}^{O}$ then in addition $\sigma_{2} \rightarrow 1$ and $\sigma_{1} \rightarrow 0$. For fixed $\epsilon>0$ time spent in hegemony $\sigma_{1}+\sigma_{2}$ declines with outside influence $A_{0}$ and as $\rho_{1} \rightarrow 0$ it approaches $2 / L$.

Notice that $1 / L$ represents the size of a unit of land relative to the total amount of land. In this model it represents the amount of land that an invader must successfully conquer to get a "toehold" enough to have an appreciable chance of success. As this grows smaller, the fraction of time there is a hegemony falls to zero. In other words, strong outside forces, and a small "toehold" needed for success means little hegemony.

We can summarize the proposition by saying that with strong outsiders there is no tendency towards hegemony, while with weak outsiders the tendency is towards a hegemony of the stronger state. Notice that the circumstances that favor hegemony are exactly the same that favor the society with greater state power. Hegemony and high state power go hand in hand. The circumstances under which we might expect to see institutions with less than maximum state power for appreciable amounts of 
time are circumstances where hegemony is uncommon and competing states more likely.

From an evolutionary perspective what matter is fitness - in this case state power. From an economic perspective we are not so interested in what level of state power is favored by evolution, but rather what it implies about institutions. For this we have to return to the static model. Since we are limited to comparing two sets of institutions, let us suppose that society 2 maximizes state power, that is, has exclusivity $\chi_{2}=\chi^{*}$ at the peak of the state power function $a^{O}(\chi)$. Without significant outside influence, we will generally see a hegemony of these institutions. This may be more or less exclusivity than the weaker society $\chi_{1}$ : the alternative society may be excessively exclusive or insufficiently exclusive. An interesting case is where the alternative society has institutions that maximize welfare: $\chi_{1}=\hat{\chi}$. From Theorems 1 and 2 we conclude that absent significant outside influence there will be a hegemony that will be inefficient and excessively extractive. By contrast, when there is significant outside influence, hegemony will be much less common, and efficient institutions will persist more frequently.

\section{Generalized Evolutionary Dynamics}

We are now going to generalize the static and dynamic models of the previous sections to seek a broader theorem about the emergence and nature of hegemony. We particularly want to avoid arbitrary assumptions about equilibrium versus nonequilibrium behavior, the number and nature of societies that might compete with one another, and the functional form of the conflict resolution function.

To generalize the static model we allow for an arbitrary finite list of societies $j=1, \ldots, M$. Each society $j$ has a set of players $i=1,2, \ldots, N_{j}$, although as in the example we understand these to be player roles that may involve representative individuals or collusive groups (in the example $N_{j}=2$ ). Each player has a finite set of actions $a_{i j} \in A_{i j}$ and we denote by $a_{j} \in A_{j}$ the corresponding action profiles. We do not explicitly model utility and incentive constraints, but assume rather that for each society there is a set of equilibrium profiles $E_{j} \subset A_{j}$. These are the profiles for which incentive constraints are satisfied - although the solution concept might depend on the context - in the example $E_{j}$ is a singleton containing the unique Stackelberg equilibrium in which state officials are the leader. We allow the possibility that $E_{j}$ is empty. Finally, there is a map from profiles to state power: $\gamma_{j}: A_{j} \rightarrow \Re_{+}$. 
Next we consider evolutionary dynamics. Each society at a moment of time $t=1,2, \ldots$ plays an action profile $a_{j t}$ and controls an integral amount of land $L_{j t}$ where $\sum_{j=1}^{M} L_{j t}=L$. If $L_{j t}>0$ we refer to a society as active, otherwise it is inactive.

In the dynamic example of the previous section we constrained action profiles to lie in $E_{j}$. We now drop the assumption that incentive constraints are satisfied at every moment of time, and instead describe a simple learning process by which individuals modify their actions and expectations over time.

We start by considering what a steady state of a learning process should be like. Two things should be true: first, players should expect that today will be the same as yesterday; second, given that expectation, it should be optimal to play the same way as yesterday. In other words, what happened yesterday should be an equilibrium, and in addition that equilibrium should be expected to recur today. In a learning process, the expectation that today should be the same as yesterday will be based on having observed that in the past this has indeed been true. Suppose that we are not yet in a steady state but in fact yesterday was an equilibrium so that $a_{j t-1} \in E_{j}$ and today is the same as yesterday so that $a_{j t}=a_{j t-1}$. A simple model of learning is to assert that in this case that there is a chance $1>\psi_{j}>0$ that expectations of tomorrow are that it will be the same as today - that we enter a steady state. ${ }^{13}$ To indicate this, we introduce a state variable $b_{j t}$ that can take on two values, 1 for steady state expectations and 0 otherwise. When $b_{j t}=1$ we say that society $j$ is stable. If $a_{j t} \notin E_{j}$ then necessarily $b_{j t}=0$. If $a_{j t} \in E_{j}$ and $b_{j t}=1$ then $a_{j, t+1}=a_{j t}$ and if $L_{j, t+1}>0$ then $b_{j, t+1}=b_{j t}=1$ that is, once an active society achieves a steady state it stays there as long as it remains active.

For unstable societies in which $b_{j t}=0$ we assume that there is a transition function $P\left(a_{j, t+1} \mid a_{j t}\right)>0$ that puts positive weight on all profiles. In other words, when people are unsure about the future there is a degree of randomness in their behavior - charismatic leaders may arise, populist nonsense may be believed and so forth. ${ }^{14}$

\footnotetext{
${ }^{13}$ Assuming that the system is always in equilibrium as we did in the example is not consistent with this formulation nor is the example consistent with the assumption below requiring "duplicate" institutions. It is possible to tweak the general model to allow the example as a special case while preserving the main theorem. As the special nature of the example is hard to justify and in any case we already know from direct computation that the theorem holds in it, we will not complicate the general model.

${ }^{14}$ This dynamic is essentially a simplified version of the stochastic individual learning procedure
} 
Finally, we assume that inactive societies are unstable. Notice that an inactive society becomes relevant only when it gains some land. This represents a group adopting a new set of institutions. We would not expect that people in a newly created society would instantly be in equilibrium: the assumption that inactive societies are unstable is a simple way of modeling the idea that when a society becomes active for the first time it is not stable and there is an element of randomness in the way in which players initially play. As inactive societies represent "potential" institutions, we also wish to allow the possibility that when groups experiment with institutions they experiment with existing institutions but use different action profiles. That is, just because an active society uses, say, a constitutional monarchy is no reason a break-away group of innovators should not also try to use a constitutional monarchy but taking different actions in hope of finding a better equilibrium.

To make precise the idea that it is possible to experiment with existing institutions, define two societies $j, j^{\prime}$ to use identical institutions if $A_{j}=A_{j^{\prime}}, E_{j}=E_{j^{\prime}}$ and $\gamma_{j}=\gamma_{j^{\prime}}$. Formally, we assume that for every society $j$ there exists a society $j^{\prime} \neq j$ with identical institutions.

Stepping back, the overall state vector at time $t$ is $s_{t}=\left\{a_{j t}, L_{j t}, b_{j t}\right\}_{j=1}^{J} \in S$, where $b_{j t}$ is constrained to be 0 when either $L_{j t}=0$ or $a_{j t} \notin E_{j}$, and evolves according to a Markov process $M(\epsilon)$ that depends on a parameter $\epsilon \geq 0$. We will study the process for small $\epsilon$. To fully specify this process on $S$ we must indicate how land is gained and lost.

As in the example the movement of land between societies is governed by a conflict resolution function - except that now we have to contend with the possibility of many societies. As before we continue to assume that at most one unit of land changes hands in any given period. Define aggregate state power to be $\Gamma_{j t}=L_{j t} \gamma_{j t}$ with $\Gamma_{t}$ and $\Gamma_{-j, t}$ being the corresponding profile of these aggregates and those of opponents to society $j$. We assume that the probability that society $j$ is disrupted and loses a unit of land $\pi_{j t}=\pi\left(b_{j t}, \Gamma_{j t}, \Gamma_{-j, t}\right)[\epsilon]$ depends on the stability of the society and on aggregate state power of the society and that of rival societies. Notice that since at most one unit of land can change hands each period $\sum_{j=1}^{M} \pi_{j t} \leq 1$ and the shocks must necessarily be correlated. The unit of land that is lost is gained by a society chosen randomly according to the function $\lambda\left(k \mid j, \Gamma_{t}\right)>0$ for $k \neq j$ and

that Foster and Young [26] introduce and for which they show Nash equilibrium is stochastically stable. 
$\lambda\left(j \mid j, \Gamma_{t}\right)=0$.

We make several assumptions about the conflict resolution function $\pi\left(b_{j}, \Gamma_{j}, \Gamma_{-j}\right)[\epsilon]$. First we assume that for $\epsilon>0$ we have $\pi\left(b_{j}, \Gamma_{j}, \Gamma_{-j}\right)[\epsilon]>0$. Second we assume that it is symmetric in $\Gamma_{-j}$, that is the names of the societies do not matter, only their strength. Third, we assume that it is monotone: non-increasing in $\Gamma_{j}$ and non-decreasing in $\Gamma_{-j}$. Fourth, we assume that it is convex in $\Gamma_{-j}$ which means that concentrated forces are more dangerous than divided ones.

Fifth, we assume that an unstable society always has an appreciable chance of losing land meaning that $\pi\left(0, \Gamma_{j}, \Gamma_{-j}\right)[\epsilon]>0$ independent of $\epsilon$. The idea is that when expectations of the future are uncertain players have a choice between experimenting with different actions - or with different institutions. Under our assumption that institutions can change on at most a single unit of land in a single period, experimentation with institutions means that a single unit of land is lost. Notice that the stability of opposing societies does not matter: how disruptive opponents are depends upon their strength and not upon whether or not they are stable. Of course if they are not stable, the actions taken by that society are likely to change in the future, and as a consequence their future ability to be disruptive may be greater or less than their current ability.

Our final and key assumption concerns the case of a stable society facing a single opponent. That is except for a single $k \neq j$ all the components of $\Gamma_{-j}$ are zero. In this case we assume that the conflict resolution function has resistance defined by

$$
r\left(1, \Gamma_{j}, \Gamma_{-j}\right) \equiv \lim _{\epsilon \rightarrow 0} \frac{\log \pi\left(1, \Gamma_{j}, \Gamma_{-j}\right)[\epsilon]}{\log \epsilon}=q\left(\frac{A_{0}+\Gamma_{j}}{A_{0}+\Gamma_{k}}\right)
$$

where for some $\underline{\phi}>1$ we have $q(\phi)=0$ for $\phi \leq \underline{\phi}$ and $q(\phi)$ strictly increasing for $\phi \geq \phi$. We also assume the regularity condition that if $r\left(1, \Gamma_{j}, \Gamma_{-j}\right)=0$ then $\lim _{\epsilon \rightarrow 0} \pi\left(1, \Gamma_{j}, \Gamma_{-j}\right)[\epsilon]=0$. These generalize the assumptions concerning resistance in the example, allowing for an arbitrary function form, but keeping the threshold between zero and positive resistance.

We have now defined a Markov process $M(\epsilon)$ on the state space $S$. Within the state space $S$ we identify certain classes of states as hegemonic. A hegemony $s_{t}$ at $\left(j, a_{j}\right)$ means that $a_{j t}=a_{j} \in E_{j}$, that society $j$ is stable $b_{j t}=1$, and that society $j$ has all the land $L_{j t}=L$. We assume that there is at least one hegemonic class that is, that the set $E_{j}$ is nonempty for at least one $j$. For any hegemonic class we 
can define $\Gamma\left(s_{t}\right)=\Gamma_{j}\left(a_{j}\right)$ to be the state power of the hegemonic society. ${ }^{15}$

We can now describe the stationary distribution $\mu(\epsilon)$ of the Markov processes $M(\epsilon)$ - this tell us how frequently different states will occur.

Theorem 4. [Main Theorem] For $\epsilon>0$ there is a unique $\mu(\epsilon)$ that places positive weight on all states. As $\epsilon \rightarrow 0$ there is a unique limit $\mu$. There is a critical value of $\underline{A}_{0}>0$. If $A_{0}>\underline{A}_{0}$ then $\mu$ places positive weight on all states. If $A_{0} \leq \underline{A}_{0}$ then $\mu$ places weight only on hegemonic classes that have maximal state power within the class of hegemonic classes.

We review here some of the important elements of the proof - the remaining details can be found in Web Appendix 1. Examining the role of $A_{0}$ we see that hegemonic classes can be ranked by their state power $\Gamma\left(s_{t}\right)$ with $\Gamma^{*}$ the maximal state power. The resistance to disruption in a hegemonic classes is

$$
q\left(\frac{A_{0}+\Gamma\left(s_{t}\right)}{A_{0}}\right)
$$

which is non-decreasing in $\Gamma\left(s_{t}\right)$, and is zero for

$$
\Gamma\left(s_{t}\right) \leq A_{0}(\underline{\phi}-1)
$$

and strictly increasing for larger $\Gamma\left(s_{t}\right)$. Take $\underline{A}_{0}=\Gamma^{*} /(\underline{\phi}-1)>0$. Then if $A_{0} \geq \underline{A}_{0}$ the resistance of all hegemonic classes is zero: this implies that there are no absorbing hegemonic classes when $\epsilon=0$.

Now suppose $A_{0}<\underline{A}_{0}$. Then any hegemonic class for which $\Gamma\left(s_{t}\right)>A_{0}(\underline{\phi}-1)$ is absorbing when $\epsilon=0$ since the probability of disruption is zero. If $A_{0}<\underline{A}_{0}$ but sufficiently close, then the only such class will be ones with state power $\Gamma^{*}$. Otherwise we use a method of Ellison to show that only hegemonic states with state power $\Gamma^{*}$ get weight in $\mu$.

The method of Ellison requires us to compute the least resistance path from one absorbing hegemonic steady class $\left(j, a_{j}\right)$ to another. It turns out this is easy to compute. The key is that the least resistance to losing a unit of land occurs when there is a single opponent who is as strong as possible. This occurs when the opponent is a society $k$ and profile $a_{k}$ such that $\gamma_{k}\left(a_{k}\right)$ is maximal over all societies

\footnotetext{
${ }^{15}$ There are generally many states making up a hegemonic class: these differ in the action profiles used by inactive societies. Note that the resistance of moving from one state in a hegemonic class to another is zero since by assumption inactive societies are unstable and have an appreciable chance of moving to each different action profile.
} 
and profiles. Such a $\left(k, a_{k}\right)$ may not be an equilibrium and may not be stable, but that does not matter, because there is an appreciable probability that it keeps doing the same thing long enough to overrun $\left(j, a_{j}\right)$. We refer to it as a barbarian horde. The resistance to the barbarian horde taking over is Ellison's radius $R_{j}\left(a_{j}\right)$ which is strictly increasing in $\gamma_{j}$. Moreover, once the barbarian horde has taken over, the resistance to reaching any other absorbing hegemonic steady class is zero.

Because the least resistance to reaching every other absorbing hegemonic class is the same amount $R_{j}\left(a_{j}\right)$ we can show that Ellison's co-radius is

$$
C R_{j}\left(a_{j}\right)=\min _{\left(k, a_{k}\right) \in H \backslash\left(j, a_{j}\right)} R_{k}\left(a_{k}\right)
$$

where $H$ are the hegemonic absorbing classes. Ellison shows that as $\epsilon \rightarrow 0$ the ratio of time during which $\left(j, a_{j}\right)$ has a hegemony to the time at which it does not is approximately

$$
1 / \epsilon^{R_{j}\left(a_{j}\right)-C R_{j}\left(a_{j}\right)} .
$$

If $\left(j, a_{j}\right)$ attains state power $\Gamma^{*}$ then $R_{j}\left(a_{j}\right)>C R_{j}\left(a_{j}\right)$ and in the limit this ratio goes to infinity: most of the time there is a hegemonic class that maximizes state power.

Remark 1. (Relation to Literature on Group Evolution) The novelty of our approach lies in our treatment of incentive compatibility. Existing literature in the area mainly focuses on the interplay between individual and group evolutionary selection: individual behavior which increases fitness of a group, typically some form of "generosity", may be harmful for individual fitness. This is the case both in the Haystack Model as in Maynard Smith [40] or Richerson and Boyd [44] and in Bowles' model of conflict and evolution (Bowles [13]). The equilibrium dimension in the group selection literature is generally missing. One exception is Boyd and Richerson [15] who consider a setting with multiple Evolutionary Stable Strategies and show that group selection can be operative at the level of the equilibrium.

What does evolutionary theory enable us to conclude about state institutions? How do the general results compare to that of the example? First, the fact that incentive constraints are not always satisfied makes little difference. By assumption the learning dynamic is "fast" relative to the evolutionary dynamic. We think empirically this is the correct assumption. In situations involving significant social disruption - for example in refugee camps - people quickly learn how to behave and what to expect and social stability - and equilibrium - no matter how unpleasant and institutionally ineffectual - quickly reigns. Note however that during periods of 
severe conflict leading to the fall of institutions that have been long stable, the fact that incentive constraints need not hold in the short run means that unstable and incentive incompatible barbarian hordes will predominant for a brief period.

Returning to our simple example of institutional differences indexed by the exclusivity parameter $\chi$ we see that the results of the simple two-society evolutionary model are reinforced. Since we now allow for many potential societies, it now natural to assume that both state power maximizing institutions $\chi^{*}$ and efficient institutions $\hat{\chi}$ are present. Once again we conclude that absent significant outside influence there will be a hegemony that will be inefficient and excessively extractive, and indeed it will be a hegemony of $\chi^{*}$.

Notice that we have assumed away technological differences. Exogenous technological differences can easily be introduced into the model - with the obvious conclusion that given the same institutions and absent significant outside influence we expect a hegemony of the superior technology. We do not think, however, that exogenous technological differences are that interesting: more interesting are endogenous technological differences that arise from difference in institutions. Unlike the example, the general model of this section is broad enough to allow for models in which different institutions lead to different levels of technology ${ }^{16}$. We do not examine such models here, but it provides an interesting area for future research.

\section{Conclusion}

Readers of grand theories of history such as those of McNeil [41], Cipolla [17], Diamond [20] or Acemoglu and Robinson [3] will not find surprising the idea that ideas are spread by the conquest of the less advanced by the more advanced - indeed it seems almost ubiquitous in their anecdotes and discussions. Missing from these accounts, however, is a model of dynamic competition between conflicting societies. Here we introduce such a model and find that there is a tendency towards hegemony when outside forces are weak - but less so when they are strong. ${ }^{17}$ We also find that these hegemonies tend to maximize state power and that this results in inefficiently high exclusiveness which in turn determines inefficiently high extractiveness, that is high taxes, high income for state officials, low income for producers, and low welfare.

\footnotetext{
${ }^{16}$ As the model does not allow for the possibility of continuing growth, it is not broad enough to study technologies that lead to different long-run growth rates.

${ }^{17}$ A recent empirical paper on the relation between warfare and institutions in the Italian Risorgimento is Dincecco, Federico and Vindigni [21].
} 
An evolutionary model of the type introduced here has dynamics driven by "luck," and the intuition of the results follows from understanding this luck. To revolt successfully against a large powerful hegemonic society requires a considerable amount of luck. The larger and more powerful the hegemonic society is, the more luck is required, and so the more persistent it is likely to be. When there are strong outside influences to support the rebels less luck is required. There is an intuition here as well for the short-lived empires of Alexander the Great, Ghengis Khan or Tamurlane. The best kind of luck to have in order to successfully overwhelm a powerful neighbor is to have a great deal of military power: a strong military organization, good technology - and a charismatic and brilliant leader. Even better luck is to have that leader convince his followers to set aside their incentive constraints. Such luck will not last long - eventually warriors or their descendants will prefer to follow their incentives and consume "jewelry" rather than "swords" - but the luck can last long enough to conquer the relevant world. These are the barbarian hordes in the proof of our main theorem.

The theory has many implications. In the introduction we gave a broad view of hegemony and the connection to the strength of outside forces. Here we give some more speculative thoughts about institutions and history seen through the lens of hegemonic state power and outside influence.

Hong Kong and Singapore. We note that the libertarian success stories favored by Milton Friedman in Singapore and Hong Kong were protected from outside influence - in the case of Hong Kong by the British military, and in the case of Singapore by a water barrier. An aspect of the theory worthy of future exploration is that because there is less scope for competition small geographically protected areas are likely to have a broader range of social arrangements - both efficient and inefficient - than larger areas. ${ }^{18}$

Democracy and military spending. In the range between welfare maximization and state power maximization the theory predicts a positive relationship between exclusiveness and state power. If one takes military spending as a measure of state power this suggests that more democratic societies would generally spend less on the military than less democratic societies. This is a robust finding in the empirical political science literature: see for example Dunne and Perlo-Freeman [22] or Dunne

\footnotetext{
${ }^{18}$ The wide range of (admittedly very primitive) social arrangements in New Guinea may be a case in point.
} 
et al [23].

Decreasing exclusiveness. Analyses such as those of Hoffman and Rosenthal [33] argue that the transition from absolute to constitutional monarchy in Europe was determined by the higher tax revenue to be employed for military purposes which a parliament could generate. This can occur in our model if technological change increases the efficiency of tax collection $\tau$ in which case it will reduce the optimal degree of exclusiveness. For example improved military technology - the development of firearms, for example - can improve the efficiency of tax collection (raise $\tau$ ) resulting in both state power maximizing and welfare maximizing levels of exclusiveness declining.

Technology and state power. We have modeled the effect of exclusiveness on output as taking place through the tax system. There can also be a direct effect of exclusiveness lowering productivity as suggested for example in Acemoglu and Robinson [3]. ${ }^{19}$ As indicated above, it is possible to study models of endogenous technology driven by institutional differences in our general evolutionary model. We do not expect that it will change the general nature of the conclusions from the simple example, but may have additional interesting implications. In particular the nature of technology may interact with institutions. For example, at the beginning of the cold war, technology favored assembly line manufacturing which is relatively amenable to central planning, and so the Soviet Union, a particularly exclusive and extractive system accumulating military power, was able to compete successfully with the United States. By contrast as technology changed to favor greater decentralization and inclusiveness, it is likely that the enormous growth of GDP in the United States relative to the Soviet Union made it impossible for the Soviet Union to continue to compete.

Nationalism. We have characterized institutions by exclusiveness - the extent to which state power is unchecked in collecting taxes. Another dimension in which institutions may differ is in the extent to which tax revenue is checked in being used as external state power. It is simple to modify the model to include another multiplier which we might think of as "nationalism" which converts the portion of tax revenue devoted to state power to actual (external) state power. At the extreme we

\footnotetext{
${ }^{19}$ There can also be a direct benefit to government officials of state power, for example, they may have a taste for warfare as in Hoffman [32] - this would not change the qualitative nature of our results.
} 
can think of this as being zero in the case of Japan where the constitution prohibits the use of military force externally. ${ }^{20}$ Such a multiplier has no implication for welfare, but obviously state power is maximized when the coefficient of nationalism is one. In other words: nationalism is a necessary characteristic of long-lived societies - which may help to explain its prevalence. ${ }^{21}$

An evolutionary model is a model of the very long-run and historically hegemonic societies have lasted many centuries. Moreover, the decline and fall of societies according to the model is driven by infrequent bad luck. Applying the model to current affairs is particularly speculative, more so given that modern institutions are quite recent with the oldest ones being those of the U.S. ${ }^{22}$ However, consistent with the theory the U.S. - which has a very high level of military expenditure - has had an effective hegemony over the North American continent for 237 years. We notice also that despite modern technology the large oceans appear to still provide a formidable military obstacle - it seems unlikely that either the United States or China is likely to bypass these barriers to establish a world hegemony. With five major "rivals" in Eurasia - Europe, Russia, China, India and the Islamic block - we may hope that the U.S. may play the role in the future of the Eurasian continent that we believe England did in continental Europe - that of preventing hegemony and preserving competition. ${ }^{23}$

\section{Appendix 1: Historical Data and Computations}

Summary of Chinese dynastic history taken from Table 1.1 of Maddison [38].

- 221 BCE - 206 BCE: Ch'in (hegemonic); 206 BCE - 8 CE: early Han (hegemonic); 8 CE - 23 CE: interregnum

- 23 CE - 220 CE: later Han (hegemonic); 220 CE - 589 CE: Empire disintegrated

\footnotetext{
${ }^{20}$ In an earlier version of this paper Levine and Modica [37] we considered "expansionism" which allowed the use of state power for defense but not for offense. However, we showed that under mild conditions such societies will have little evolutionary success.

${ }^{21}$ Notice that just as exclusiveness may have a direct effect on technology, so may nationalism: for example, the same desire to protect against outsiders and to conquer them may also inhibit the peaceful arrival of productive immigrants and so lower output. Never-the-less unless this force is very strong, maximizing state power will involve a substantial amount of nationalism.

${ }^{22}$ The European Union - which includes England - as well as current institutions in China and India are all post World War II.

${ }^{23}$ Note that the ratio of U.S. to Eurasian population is similar to that of England to continental Europe.
} 
- $589 \mathrm{CE}$ - $617 \mathrm{CE}$ : Sui (hegemonic); $618 \mathrm{CE}$ - $906 \mathrm{CE}$ : T’ang (hegemonic); 906 CE - 960 CE: empire disintegrated

- 960 CE-1127 CE: Sung(hegemonic); 1127 CE - 1279 CE: interregnum (Jurchen/Yuan in North, Southern Sung)

- 1279 CE - 1368 CE: Yuan (hegemonic); 1368 CE - 1644 CE: Ming (hegemonic)

- 1644 CE - 1911 CE: Chi'ng (hegemonic); 1911 CE - 1949 CE: interregnum

- 1949 CE - 2013 CE: Communist (hegemonic)

The total number of years covered is 2234 . There are five interregna totally 630 years, so $72 \%$ of the period is hegemonic.

Summary of ancient Egyptian history taken from Shaw [47].

- 2686 BCE - 2160 BCE: Old Kingdom (hegemony); 2160 BCE - 2055 BCE: first intermediate period

- 2055 BCE - 1650 BCE: Middle Kingdom (hegemonic); 1650 BCE - 1550 BCE: second intermediate period

- 1550 BCE - 1069 BCE: New Kingdom (hegemonic)

The total number of years covered is 1617 . There are two interregna totally 205 years, so $87 \%$ of the period is hegemonic.

Summary of ancient Persian history taken from Daryaee $[18]^{24}$

- 550 BCE - 330 BCE: Achaemenid Persian Empire (hegemonic); 330 BCE 250 BCE: interregnum

- 250 BCE - 114 CE: Parthian Empire (hegemonic); 114 CE - 224 CE: interregnum

- $224 \mathrm{CE}$ - $651 \mathrm{CE}$ : Sassanian Empire (hegemonic)

The total number of years covered is 1201 . There are two interregna totally 190 years, so $84 \%$ of the period is hegemonic.

\footnotetext{
${ }^{24}$ Additional information about the Parthian Empire from Wright [48]. Note that the conventional dates of the Parthian Empire conclude with the Sassanian Empire, but the hegemony of the Parthian Empire appears to have ended following the war with Rome in 114 AD, so we take that as the end date.
} 


\section{Additional history}

We count the hegemony of Rome from Augustus in $27 \mathrm{BCE}$ to the permanent division into the Eastern and Western Empires in $395 \mathrm{CE}$, a period of 422 years. The Western Empire did not maintain a hegemony for a significant period after this. We date the end of the hegemony of the Eastern Empire to the expansion of the Caliphate in 814 CE. - 395 a period of 429 years.

In England we date the beginning of the hegemony from the Norman conquest in 1066 , a period of 947 years.

We date the hegemony of the Ottoman Empire from the conquest of Egypt in 1517 to the Greek revolution in 1821, a period of 304 years.

Demographic data taken from Maddison [39]

Ratio of population of Mongolia to China in $1820 \mathrm{CE}$ (the earliest date for which there is an estimate of the Mongolian population): .2\%.

Ratio of population of Scandinavia to Western Europe excluding Greece and the British Isles in 1000 CE 5\%.

Ratio of population of United Kingdom to all of Western Europe: In $1000 \mathrm{CE}$ it is $8 \%$ and remains relatively stable until it rises in the early late 1800 s, rising to $19 \%$ in $1820 \mathrm{CE}$ and remaining relatively stable since then.

Estimate of ratio of population of Central Asia to India in $1820 \mathrm{CE}$. The ratio of the population of Afghanistan to India in 1820 is 1.6\%. Data for the rest of Central Asia is not available until $1950 \mathrm{CE}$. We computed the ratio of the population of the rest of Central Asia (the Soviet "stans": Kazakhstan, Kyrgyzstan, Tajikstan, Turkmenistan, and Uzbekistan) to Afghanistan in $1950 \mathrm{CE}$ when data is available as being about double that of Afghanistan. Assuming that ratio is about the same as in $1820 \mathrm{CE}$ we estimate the overall ratio of the population of Central Asia to India in $1820 \mathrm{CE}$ as about $5 \%$.

\section{Appendix 2: Analysis of the Static Example}

Recall the requirements for an economy to be proper: $G(b)=0$ at $b=0$ and for

$b \geq \bar{b} \equiv(1-c) / \tau$ while for $0 \leq b \leq \bar{b} G(b)$ is twice continuously differentiable with $G^{\prime \prime}(b)<0$. Moreover, $G^{\prime}(0)>1$ and $G^{\prime}(b)+b G^{\prime \prime}(b)$ is decreasing. For $0 \leq b \leq \bar{b}$ $\Pi(b)$ is twice continuously differentiable, decreasing and $\Pi^{\prime \prime}(b)<0$ with $\Pi(b)=0$ for $b \geq \bar{b}$. Finally, $\Pi(b)-G(b)$ is decreasing.

Proposition 1. The linear quadratic economy is proper. 
Proof. The problem of the producer is to maximize

$$
u^{P}=(1-\bar{\tau}) a^{P}-\left[c a^{P}+(1 / 2)(1-c)\left(a^{P}\right)^{2}\right]+\gamma a^{O}
$$

where $\bar{\tau}=\min \left\{1, \tau \chi a^{O}\right\}$. The derivative of $u^{P}$ is $(1-\bar{\tau})-\left[c+(1-c) a^{P}\right]$. This is negative for all $a^{P}$ if $\bar{\tau}>1-c$, otherwise it hits zero at $1-\bar{\tau} /(1-c)$. Thus optimal effort is given by

$$
a^{P}=\max \left\{0,1-\frac{\bar{\tau}}{1-c}\right\}
$$

Suppose $b<\bar{b} \equiv(1-c) / \tau$. Recall that $\bar{\tau}=\min \{1, \tau b\}$. Since $b<\bar{b}$ we have $\tau b<1-c \leq 1$ so $\bar{\tau}=\tau b$. Hence in this case

$$
a^{P}=1-\frac{\bar{\tau}}{1-c}
$$

Suppose $b \geq \bar{b} \equiv(1-c) / \tau$. If $\tau b>1$ then $\bar{\tau}=1 \geq 1-c$. If $\tau b \leq 1$ then $\bar{\tau}=\tau b \geq 1-c$. Hence in this case $a^{P}=0$.

Tax revenue is $G(b)=\bar{\tau} a^{P}$. If $b \geq \bar{b}$ this is zero. Otherwise

$$
G(b)=\tau b\left[1-\frac{\tau b}{1-c}\right]
$$

which is obviously concave. From this expression we see that $G^{\prime}(0)>1$ is implied by $\tau>1$. Moreover

$$
G^{\prime}(b)+b G^{\prime \prime}(b)=\tau-b \frac{4 \tau^{2}}{1-c}
$$

is obviously decreasing in $b$.

Profit is $\Pi(b)=G(b)+u^{P}-\gamma a^{O}$. If $b \geq \bar{b}$ this is zero. Otherwise we have

$$
\Pi(b)=\frac{1-c}{2}\left[1-\frac{\tau b}{1-c}\right]^{2}+\tau b\left[1-\frac{\tau b}{1-c}\right] \quad V^{\prime}(b)=-\frac{\tau^{2} b}{1-c}
$$

Thus profit is decreasing in $b$ and $\Pi^{\prime \prime}(b)<0$.

Finally for $b \leq \bar{b}$ we have

$$
\begin{gathered}
\Pi(b)-G(b)=(1-\bar{\tau}) a^{P}-\left[c a^{P}+(1 / 2)(1-c)\left(a^{P}\right)^{2}\right] \\
=(1-\bar{\tau})\left[1-\frac{\bar{\tau}}{1-c}\right]-c\left[1-\frac{\bar{\tau}}{1-c}\right]-\frac{1}{2}(1-c)\left(1-\frac{\bar{\tau}}{1-c}\right)^{2} \\
=\frac{1}{2}(1-c)\left(1-\frac{\bar{\tau}}{1-c}\right)^{2}
\end{gathered}
$$

which since $\bar{\tau}=\min \{1, \tau b\}$ and $\bar{\tau}<1-c$ is decreasing in $b$. 
Theorem. [1 from the text] In a proper economy there is a unique equilibrium level of state power $a^{O}(\chi)$, and it is single peaked in $\chi$; so there is a unique argmax $\chi^{\star}>0$. There is a unique welfare maximizing level of exclusivity $\hat{\chi}$, and $\hat{\chi} \leq \chi^{\star}$. There is a $\bar{\gamma} \geq 1$ such that if $\gamma \leq \bar{\gamma}$ then $\hat{\chi}<\chi^{\star}$.

Proof. The official's utility is given by $u^{O}=G\left(\chi a^{O}\right)-a^{O}$, where $G(b)$ has $G^{\prime \prime}(b)<0$ on $[0, \bar{b}]$ and $G(b)=0$ for $b>\bar{b}$. Hence the maximum with respect to $a^{O}$ is unique and is either 0 if $\chi G^{\prime}(0)<1$ or the unique to the first order condition $\chi G^{\prime}\left(\chi a^{o}\right)=1$ otherwise. In the latter case, we have from the implicit function theorem

$$
\frac{d a^{O}}{d \chi}=-\frac{G^{\prime}(b)+b G^{\prime \prime}(b)}{\chi^{2} G^{\prime \prime}(b)}
$$

and $G^{\prime}(b)+b G^{\prime \prime}(b)$ decreasing implies the objective is continuous and single peaked and so has a unique maximum $a^{O}(\chi)$. Note that since $G^{\prime}(0)>1$ from the first order condition the solution $a^{O}(1)>0$ implying a positive level of state power is feasible, and hence that the argmax $\chi^{\star}>0$.

Welfare is $W\left(a^{O}\right)=\Pi\left(\chi a^{O}\right)-(1-\gamma) a^{O}$ and since $\Pi^{\prime \prime}(b)<0$ in $[0, \bar{b}]$ there is a unique maximum at some $\hat{a}^{O}$. Suppose $\chi>\chi^{\star}$. Then there is a $\chi^{\prime}<\chi^{\star}$ with $a^{O}\left(\chi^{\prime}\right)=a^{O}(\chi)$. Since $\Pi(b)$ is decreasing, this implies that $W\left(a^{O}\left(\chi^{\prime}\right)\right)>$ $W\left(a^{O}(\chi)\right)$. Hence $\hat{\chi} \leq \chi^{\star}$, and exact equality is possible only if either $\chi^{\star}=0$ or $\hat{a}^{O}>\max _{\chi} a^{O}(\chi)$. But $\chi^{\star}>0$ and $\hat{a}^{O}\left(\chi^{\star}\right)>0$; and if $\gamma<1$ then $W\left(a^{O}\right)$ is decreasing, so $\hat{a}^{O}=0<\hat{a}^{O}\left(\chi^{\star}\right)$.

Theorem. [2 from the text] In a proper economy profits $\Pi\left(\chi a^{O}(\chi)\right)$ is decreasing in $\chi$, while tax revenues $G\left(\chi a^{O}(\chi)\right)$, tax power $\chi a^{O}(\chi)$, and the utility of state officials $u^{O}\left(\chi, a^{O}(\chi)\right)$ are all increasing in $\chi$. For $\chi \geq \hat{\chi}$ producer utility is decreasing in $\chi$ and if $\gamma<1$ so is welfare. If $\gamma \geq 1$ welfare is decreasing for $\hat{\chi} \leq \chi \leq \chi^{\star}$.

Proof. The first order condition for maximizing $u^{O}$ is $\chi G^{\prime}(b)=1$ so by the envelope theorem we have $d u^{O} / d \chi=a^{O}(\chi) G^{\prime}\left(\chi a^{O}(\chi)\right)=a^{O}(\chi) / \chi>0$. So the utility of state officials is increasing in $\chi$; and from $d b / d \chi=-1 / \chi^{2} G^{\prime \prime}(b)>0$ tax power is also increasing in $\chi$. For tax revenues $G\left(\chi a^{O}(\chi)\right)$ since tax power is increasing in $\chi$ it is sufficient that $G^{\prime}\left(\chi a^{O}(\chi)\right)>0$, which follows from the first order condition for maximizing $u^{O}$. Profits decrease with $\chi$ because it is assumed to be decreasing in tax power which increases with $\chi$.

For $\hat{\chi} \leq \chi \leq \chi^{\star}$ we have $a^{O}(\chi)$ increasing, while $W\left(a^{O}\right)$ is concave in $a^{O}$ so welfare is decreasing in $\chi$. Since state official utility is increasing, it follows that producer utility must be decreasing. For $\chi>\chi^{\star}$ we have tax power $b$ increasing and state power $a^{O}$ decreasing. Since producer utility is welfare minus state official utility it is $u^{P}=\Pi(b)-G(b)+\gamma a^{O}$ and $\Pi(b)-G(b)$ is assumed to be decreasing. When $\gamma<1$ we also have welfare $W=\Pi(b)-(1-\gamma) a^{O}$ decreasing. 


\section{References}

[1] Aoki, K. (1982) "A condition for group selection to prevail over counteracting individual selection," Evolution 36: 832-42.

[2] Acemoglu, Daron and James A. Robinson (2000): "Why Did the West Extend the Franchise? Democracy, Inequality, and Growth in Historical Perspective, Quarterly Journal of Economics 115: 1167-1199.

[3] Acemoglu, Daron and James A. Robinson (2012): Why Nations Fail: The Origins of Power, Prosperity, and Poverty, Crown Publishing Group.

[4] Alesina, Alberto and Enrico Spolaore (2003): The Size of Nations, MIT University Press.

[5] Alger, I. and J. Weibull (2010): "Kinship, Incentives and Evolution," American Economic Review 100(4): 1725-1758.

[6] Bergstrom, Ted (2003): "The Algebra of Assortative Encounters and the Evolution of Cooperation," International Game Theory Review 5: 1-18.

[7] Bisin, A. (2001): "The economics of cultural transmission and the evolution of preferences," Journal of Economic Theory 97, 298-319.

[8] Bisin, A. and G. Topa (2004): "Cooperation as a transmitted cultural trait," Rationality and Society 16: 477-507.

[9] Blume, L. and D. Easley (1992): "Evolution and Market Behavior," Journal of Economic Theory 58: 9-40.

[10] Boorman, S. and P.R. Levitt (1973): "Group Selection on the Boundary of a Stable Population," Theoretical Population Biology 4: 85-128.

[11] Bottazzi G. and P. Dindo (2011): "Evolution and Market Behavior with Endogenous Investment Rules," LEM Papers Series 2010/20, Sant'Anna School of Advanced Studies, Pisa, Italy.

[12] Bowles, Samuel (2006): "Group competition, reproductive leveling and the evolution of human altruism," Science 314: 1569-72.

[13] Bowles, Samuel (2009): "Did Warfare among Ancestral Hunter-Gatherer Groups Affect the Evolution of Human Social Behaviors", Science 324: 1293-98.

[14] Bowles, Samuel, Jung-Kyoo Choi and Astrid Hopfensitz (2003): "The coevolution of individual behaviors and group level institutions," Journal of Theoretical Biology 223: 135-47.

[15] Boyd, Robert and Peter J. Richerson (1990): "Group Selection among Alternative Evolutionary Stable Strategies", Journal of Theoretical Biology 145: 331342

[16] Choi, Jung-Kyoo and Samuel Bowles (2007): "The coevolution of parochial altruism and war," Science 318: 636-40.

[17] Cipolla, Carlo (1965): Guns, Sails, and Empires: Technological Innovation and the Early Phases of European Expansion, 1400-1700.

[18] Daryaee, Touraj (ed)(2012): Persia Oxford Handbook of Iranian History, Oxford University Press. 
[19] Dekel, E. J. C. Ely and O.Yilankaya (2007): "Evolution of Preferences," The Review of Economic Studies 74(3):685-704.

[20] Diamond, Jared (1998): Guns, Germs, and Steel: The Fates of Human Societies.

[21] Dincecco, Mark, Giovanni Federico and Andrea Vindigni (2011): "Warfare, Taxation, and Political Change: Evidence from the Italian Risorgimento", The Journal of Economic History 71: 887-914

[22] Dunne, John P. and Perlo-Freeman, Samuel (2003): "The demand for military spending in developing countries", International Review of Applied Economics 17: $23-48$

[23] Dunne, John P., Perlo-Freeman, Samuel, and Smith, Ronald P. (2008): "The demand for military expenditure in developing countries: hostility versus capability", Defense and Peace Economics 19: 293-302.

[24] Ellison, Glenn (2000): "Basins of Attraction, Long Run Stochastic Stability and the Speed of Step-by-step Evolution," Review of Economic Studies 67: 17-45.

[25] Ely, Jeffrey (2002): "Local conventions," The BE Journal of Theoretical Economics.

[26] Foster, Dean and Peyton Young (2003): "Learning, hypothesis testing, and Nash equilibrium" Games and Economic Behavior.

[27] Fudenberg, Drew, David K. Levine and Eric Maskin (1994): "The folk theorem with imperfect public information," Econometrica.

[28] Fudenberg, Drew and Eric Maskin (1986): "The folk theorem in repeated games with discounting or with incomplete information," Econometrica.

[29] Garfinkel, Michelle and Stergios Skaperdas (2007): "Economics of Conflict: An Overview," Handbook of Defense Economics, Elsevier.

[30] Hausken, Kjell (2005): "Production and Conflict Models Versus Rent Seeking Models," Public Choice 123: 59-93.

[31] Hirshleifer, Jack (2001): The dark side of the force: economic foundations of conflict theory, Cambridge University Press.

[32] Hoffman, Philip T. (2013): Why Did Europe Conquer the World? forthcoming Princeton University Press.

[33] Hoffman, Philip T. and Jean-Laurent Rosenthal (2000): "Divided We Fall: The Political Economy of Warfare and Taxation", Mimeo, California Institute of Technology

[34] Kandori, Michihiro (1992): "Social norms and community enforcement," The Review of Economic Studies.

[35] Kandori, Michihiro, George Mailath, and Rafael Rob (1993): "Learning, Mutation, and Long Run Equilibria in Games," Econometrica 61: 29-56.

[36] Levine, David, Salvatore Modica, Federico Weinschelbaum and Felipe Zurita (2011): "Evolving to the Impatience Trap: The Example of the Farmer-Sheriff Game," mimeo Washington University of St. Louis.

[37] Levine, David and Salvatore Modica (2012): "Conflict and the Evolution of 
Societies," working paper, www.dklevine.com.

[38] Maddison, Angus (1998): Chinese Economic Performance in the Long-Run, OECD Development Centre, Paris.

[39] Maddison, Angus (2013): Historical Statistics for the World Economy: 1-2003 $A D$, spreadsheet available at www.gdcc.net.

[40] Maynard Smith, John (1982): Evolution and the Theory of Games, Cambridge University Press.

[41] McNeil, William (1963): The Rise of the West, University of Chicago Press.

[42] Price, George R. (1970): "Selection and Covariance," Nature 227: 520-21.

[43] Price, George R. (1972): "Extension of Covariance Selection Mathematics," Annals of Human Genetics 35: 485-90.

[44] Richerson, Peter J. and Robert Boyd (2001) "Commitment to Groups: A Tribal Instincts Hypothesis" in Evolution and the Capacity for Commitment, ed. Randolph M. Nesse, Russell Sage Foundations.

[45] Rogers D. S., O. Deshpande and M. W. Feldman (2011): "The Spread of Inequality," PLoS ONE 6(9): e24683. doi:10.1371/journal.pone.0024683

[46] Rowthorn, Robert and Paul Seabright (2010): "Property rights, warfare and the neolithic transition," Toulouse School of Economics Working Paper 10-207.

[47] Shaw, Ian (ed) (2000): The Oxford History of Ancient Egypt: Oxford University Press.

[48] Wright, Edmund (2006): A Dictionary of World History, second edition, Oxford University Press.

[49] Young, Peyton (1993): "The Evolution of Conventions," Econometrica 61: 5784. 


\section{Web Appendix 1: Proof of the Main Theorem}

Theorem. [Main Theorem from the text] For $\epsilon>0$ there is a unique $\mu(\epsilon)$ that places positive weight on all states. As $\epsilon \rightarrow 0$ there is a unique limit $\mu$. There is a critical value of $\underline{A}_{0}>0$. If $A_{0} \geq \underline{A}_{0}$ then $\mu$ places positive weight on all states. If $A_{0}<\underline{A}_{0}$ then $\mu$ places weight only on hegemonic classes that have maximal state power within the class of hegemonic classes.

Proof. First, we examine hegemonic classes more closely and explain the role of $A_{0}$. These can be ranked by their state power $\Gamma\left(s_{t}\right)$ with $\Gamma^{*}$ the maximal state power. The resistance to disruption in a hegemonic class is

$$
q\left(\frac{A_{0}+\Gamma\left(s_{t}\right)}{A_{0}}\right)
$$

which is non-decreasing in $\Gamma\left(s_{t}\right)$, and is zero for

$$
\Gamma\left(s_{t}\right) \leq A_{0}(\underline{\phi}-1)
$$

and strictly increasing for larger $\Gamma\left(s_{t}\right)$. Take $\underline{A}_{0}=\Gamma^{*} /(\underline{\phi}-1)>0$. Then if $A_{0} \geq \underline{A}_{0}$ the resistance of all hegemonic classes is zero.

If the resistance of all hegemonic classes is zero or if $\epsilon>0$ then all feasible transitions have positive probability. This implies that there is a positive probability of moving from any state to any other state. First destabilize all the stable societies by having them lose all their land. Then have each remaining unstable society lose land in such a way as to match the target land holding of the target institutions. Then change the action profiles for each society to match the target. Repeat this once, and for every society that is supposed to be stable in the target, make it stable.

Hence if the resistance of all hegemonic classes is zero or if $\epsilon>0$ the process $M(\epsilon)$ is positively recurrent, implying that $\mu(\epsilon)$ is unique and places positive weight on all states. Next, observe that the stationary distributions are the solutions of $\mu(\epsilon)=$ $M(\epsilon) \mu(\epsilon)$. Under our assumptions in the limit as $\epsilon \rightarrow 0$ we have $M(\epsilon) \rightarrow M(0)$ from which it follows that if $\mu$ is any limit point of $\mu(\epsilon)$ then $\mu$ is a stationary distribution for $M(0)$. When $A_{0}>\underline{A}_{0}$ then, as $\mu(0)$ is unique it follows that $\mu(\epsilon) \rightarrow \mu(0)$.

Now suppose $A_{0}<\underline{A}_{0}$. A theorem of Young [49] shows that from the assumption that $M(\epsilon)$ is regular it is still the case that $\mu(\epsilon)$ has a unique limit $\mu$. Now however $M(0)$ can have many stationary distributions, so the question is: which one is $\mu$ ? Notice that any hegemonic class for which $\Gamma\left(s_{t}\right)>A_{0}(\phi-1)$ is absorbing in $M(0)$ since when $\epsilon=0$ the probability of disruption is zero. On the other hand from any other type of state, the argument of the previous paragraph shows that there is a positive probability of reaching one of these absorbing classes, so all other states are transient. Hence $\mu$ can place weight only on such hegemonic classes. If $A_{0}<\underline{A}_{0}$ but sufficiently close, then the only such classes will be ones with state power $\Gamma^{*}$. However, as $A_{0}$ decreases there will be other weaker classes that are also absorbing in 
$M(0)$. However, a theorem of Ellison [24] shows that these classes have probability zero in $\mu$ and the application of Ellison's method yields other useful information about the dynamics.

Let $H$ denote the set of hegemonic absorbing classes, that is, for which $s_{t} \in h_{t} \in$ $H \Gamma\left(s_{t}\right)>A_{0}(\underline{\phi}-1)$. In addition to writing $s_{t} \in H$ we write $\left(j, a_{j}\right) \in H$ when there is a hegemonic state $s_{t}$ at $\left(j, a_{j}\right)$ in $H$.

To apply Ellison's method we must determine for each $\hat{h}_{t} \in H$ the basin consisting of states not in $\hat{h}_{t}$ for which when $\epsilon=0$ the probability of reaching $s_{t}$ is one. Suppose $\hat{h}_{t}$ is hegemonic at $\hat{s}_{t}$ and $\left(j, a_{j}\right)$, and consider states $s_{t} \neq \hat{s}_{t}$ in different classes. If $\pi\left(1, \Gamma_{j t}, \Gamma_{-j t}\right)[0]=0$, since we have assumed that united opponents are stronger than divided ones and $\phi>1$ it must also be the case that for some $k$ we have $\pi\left(b_{k}, \Gamma_{k}, \Gamma_{-k}\right)[0]>0$. Hence in this case there is no chance of $j$ losing land, and a positive probability of gaining it, meaning with probability one we return to a hegemonic $j$. On the other hand if $\pi\left(1, \Gamma_{j}, \Gamma_{-j}\right)[0]>0$ so that there is a positive chance $j$ loses land, since that will only increase the subsequent chance of losing land, there is a positive probability it will lose all its land and become absorbed in some different hegemonic state. Hence the basin are exactly those states for which $\pi\left(1, \Gamma_{j}, \Gamma_{-j}\right)[0]=0$.

The radius is defined as the least resistance path starting at a state $\hat{s}_{t} \in \hat{h}_{t}$ out of the basin. The initial resistance to losing a unit of land is

$$
q\left(\frac{A_{0}+\Gamma\left(\hat{s}_{t}\right)}{A_{0}}\right)
$$

Subsequently the greatest chance of losing another unit of land occurs when there is a single opponent who has the highest possible state power. Consider then a society $k$ and profile $a_{k}$ such that $\gamma_{k}\left(a_{k}\right)$ is maximal over all societies and profiles. Such a combination may not be an equilibrium so would be unstable, but we will assume that even if it is an equilibrium it is unstable. Notice that this combination may use the same institutions as $\hat{h}_{t}$ but this is okay because we have assumed that there are duplicate institutions. We refer to such a profile as a barbarian horde. When the opponent is a barbarian horde the resistance to losing land is smallest until the threshold $\underline{\phi}$ is reached and resistance falls to zero. Denote by $R_{j}\left(a_{j}\right)$ the sum of resistances until the threshold is reached, and notice that it is strictly increasing in $\gamma_{j}$. Once the threshold is reached there is then a zero resistance path to every other hegemonic absorbing state: the horde remains unstable and takes over all the land with no resistance. Since it is unstable, it than can lose units of land without any resistance, and there is a positive probability independent of $\epsilon$ so that the land is lost to the target hegemony.

We conclude that the radius of $s_{t}$ is $R_{j}\left(a_{j}\right)$ and this is strictly increasing in $\gamma_{j}$. On the other hand, to compute the co-radius of we must find the hegemonic absorbing state from which it takes the longest to get back to $s_{t}$. So the co-radius 
of $\left(j, a_{j}\right)$ is just

$$
C R=\min _{\left(k, a_{k}\right) \in H \backslash\left(j, a_{j}\right)} R_{k}\left(a_{k}\right) .
$$

Hence when $\left(j, a_{j}\right)$ attains $\Gamma^{*}$ so that $R_{j}\left(a_{j}\right)$ is maximal we have $R>C R$.

\section{Web Appendix 2: Detailed Analysis of the Linear/Quadratic Case}

Recall from Appendix 2 the solution to the problem of the producer:

$$
a^{P}=\max \left\{0,1-\frac{\bar{\tau}}{1-c}\right\} .
$$

The problem of the state official is to maximize

$$
u^{O}=\bar{\tau} a^{P}-a^{O}=\min \left\{1, \tau \chi a^{O}\right\} \cdot \max \left\{0,1-\frac{\min \left\{1, \tau \chi a^{O}\right\}}{1-c}\right\}-a^{O}
$$

Suppose $\tau \chi<1$. Then for all $a^{O} \leq 1$ and also $\tau \chi a^{O}<1$ so

$$
\begin{aligned}
u^{O} & =\tau \chi a^{O} \cdot \max \left\{0,1-\frac{\tau \chi a^{O}}{1-c}\right\}-a^{O}<a^{O} \cdot \max \left\{0,1-\frac{\tau \chi a^{O}}{1-c}\right\}-a^{O} \\
& =\max \left\{0, a^{O}\left(1-\frac{\tau \chi a^{O}}{1-c}\right)\right\}-a^{O}<0 \forall a^{O}>0
\end{aligned}
$$

Thus for $\tau \chi<1$ the optimal $a^{O}=0$ which gives $u^{O}(0)=0$.

Now suppose $\tau \chi \geq 1$. Then $\frac{1-c}{\tau \chi} \leq 1-c<1$. For $a^{O}>\frac{1-c}{\tau \chi}$ one has $\bar{\tau}>1-c$ so inserting $a^{W}=0$ into $u^{O}$ we get $u^{O}=-a^{O}<0=u^{O}(0)$, whence optimal choice must be in the range $a^{O} \leq(1-c) /(\tau \chi)$. In this range $\bar{\tau}=\tau \chi a^{O} \leq 1-c$ and $a^{P}=1-\frac{\bar{\tau}}{1-c}$, so

$$
u^{O}=\tau \chi a^{O} a^{P}-a^{O}=\tau \chi a^{O}-\frac{\left[\tau \chi a^{O}\right]^{2}}{1-c}-a^{O}
$$

The derivative is $\tau \chi-2 \tau \chi a^{O} \frac{\tau \chi}{1-c}-1$, so the first order condition gives

$$
a^{O}=\frac{1-c}{2} \frac{\tau \chi-1}{(\tau \chi)^{2}}=\frac{1}{2} \frac{1-c}{\tau \chi}\left(1-\frac{1}{\tau \chi}\right)<\frac{1-c}{\tau \chi}
$$

Thus

$$
a^{O}(\chi)=\max \left\{0, \frac{1-c}{2} \frac{\tau \chi-1}{(\tau \chi)^{2}}\right\}
$$

Note that $\tau \chi a^{O}(\chi)<1-c$ for all $\chi$. Thus the optimal tax rate is the following, 
increasing in $\chi$ :

$$
\bar{\tau}=\tau \chi a^{O}(\chi)=\max \left\{0, \frac{1-c}{2}\left(1-\frac{1}{\tau \chi}\right)\right\}
$$

And inserting this into optimal producer's choice we get (since $\bar{\tau}<1-c$ )

$$
a^{P}(\chi)=1-\frac{\bar{\tau}}{1-c}=1-\max \left\{0, \frac{1}{2}\left(1-\frac{1}{\tau \chi}\right)\right\}
$$

Plugging back optimal choices we can compute utilities. For $\tau \chi<1 a^{O}=u^{O}=$ $0, a^{P}=1$ and $u^{P}=(1-c) / 2$. Note that this is a "libertarian" equilibrium: officials impose no taxes because it would be unprofitable to do so and producers exert maximum effort. But state power, crucial in interactions with other societies, is zero.

For $\tau \chi \geq 1$ we have

$$
a^{P}=\frac{1}{2}\left(1+\frac{1}{\tau \chi}\right) \quad a^{O}(\chi)=\frac{1-c}{2} \frac{\tau \chi-1}{(\tau \chi)^{2}}
$$

Utility of producers can be computed to be

$$
u^{W P}=\frac{1-c}{8(\tau \chi)^{2}}\left\{(\tau \chi+1)^{2}+4 \gamma(\tau \chi-1)\right\}
$$

Utility of state officials: using $\tau \chi a^{W}=(1+\tau \chi) / 2$ and $a^{O}(\chi)$ we get

$$
u^{O}=\tau \chi a^{O} a^{P}-a^{O}=a^{O}\left(\tau \chi a^{P}-1\right)=\frac{1-c}{4}\left[1-\frac{1}{\tau \chi}\right]^{2} .
$$

